\title{
CARACTERIZAÇÃO GEOAMBIENTAL DO CAMPUS DA UNIVERSIDADE ESTADUAL DE FEIRA DE SANTANA ATRAVÉS DE MAPEAMENTO GEOTÉCNICO
}

$\underline{\text { Juliele Nascimento Jesus }}{ }^{1}$; Gracinete Bastos de Souza $^{2}$; Nadine de Jesus Santos ${ }^{3}$; Igor Ferreira de Almeida ${ }^{4}$

1. Bolsista PIBIC/ CNPq, Graduanda em Engenharia Civil, Universidade Estadual de Feira de Santana, e-mail: njjuliele@gmail.com

2. Orientadora, Departamento de Exatas, Universidade Estadual de Feira de Santana, e-mail: gracinet@uefs.br 3. Participante do projeto Integração de Dados dos Aspectos do Meio Físico do Município de Feira de Santana, BA, Departamento de Tecnologia, Universidade Estadual de Feira de Santana, e-mail: nadinesanttos@gmail.com

4. Participante do projeto Integração de Dados dos Aspectos do Meio Físico do Município de Feira de Santana, BA,

Departamento de Tecnologia, Universidade Estadual de Feira de Santana, e-mail: igor.almeidaig@gmail.com

PALAVRAS-CHAVE: UEFS; Mapeamento; Geoambiental.

\section{INTRODUÇÃO}

O campus da Universidade Estadual de Feira de Santana (UEFS) está localizado entre as coordenadas geográficas $12^{\circ} 16^{\prime} 00^{\prime}$ 'S e $38^{\circ} 58^{\prime} 00^{\prime} \mathrm{W}$, possui uma área interna de 1.096.741,67 m². Situa-se no Km 3 da BR 116 Norte, no município de Feira de Santana - Bahia (dista $108 \mathrm{~km}$ a oeste da capital, Salvador).

Esta pesquisa teve como finalidade fazer uma caracterização do meio físico e uma análise geoambiental da Universidade Estadual de Feira de Santana - BA, utilizando a técnica de mapeamento geotécnico. Para isso, fez-se um levantamento das informações pré-existentes para descrever aspectos físicos como geomorfologia, hidrologia, clima e material inconsolidado. Também foram feitos estudos para um diagnóstico da situação geoambiental, atentando para a degradação ambiental e para o uso e ocupação do terreno (área construída $\mathrm{x}$ área em construção $\mathrm{x}$ área verde): vegetação; geologia e processos erosivos presentes dentro do perímetro da universidade; as condições climatológicas e como elas são afetadas pelo desmatamento e as condições da Lagoa da Pindoba.

A realização desse trabalho é fundamental, pois beneficia tanto a comunidade acadêmica quanto a comunidade geral. Visto que é importantíssimo conhecer as características físicas e ambientais da região em estudo para fins de planejamento e ampliação do campus; para políticas voltadas a preservação do meio, conhecendo-se as condições ambientais vigentes; para entender de que forma as ações antrópicas consumadas dentro da universidade estão interligadas com o meio ambiente (positiva e negativamente) e até que ponto elas interferem no bem-estar físico e social.

\section{MATERIAL E MÉTODOS OU METODOLOGIA}

O desenvolvimento do trabalho deu-se a partir de uma revisão bibliográfica, realizando uma fundamentação teórica com os temas envolvidos na pesquisa. E, fazendo-se um levantamento sobre as informações pré-existentes sobre o município de Feira de Santana e do campus, através de artigos, monografias, relatórios anteriores e livros. Para a elaboração de mapas temáticos, espacialização e armazenamento de dados, utilizou-se um Sistema de Informações Geográficas (SIG) por meio do "software" SPRING 5.3, desenvolvido pelo Instituto Nacional de Pesquisas Espaciais (INPE). A atividade de campo teve como objetivo o reconhecimento geral do meio físico da localidade. Para que isso se concretizasse, foram feitas visitas entre os meses de março a junho de 2017, nas quais se possibilitou observar, analisar e identificar in loco a geomorfologia, o solo, a vegetação, a hidrologia, a geologia, a situação geoambiental da região e as formas de uso e ocupação do campus. 


\section{RESULTADOS E/OU DISCUSSÃO}

\section{Aspectos gerais}

De acordo com os dados obtidos na Unidade de Infraestrutura e Serviços da UEFS - UNINFRA (UEFS, 2017), a área total do terreno do campus (interno e externo) é de 1.586.053,64 $\mathrm{m}^{2}$, sendo que dessa área 95.231,39 $\mathrm{m}^{2}$ é construída (no campus e extra campus). A tabela abaixo apresenta os dados sobre a área do campus e suas divisões:

Tabela 1. Distribuição da área do campus.

\begin{tabular}{|cc|}
\hline $1.096 .741,67$ & $69,15 \%$ \\
$489.311,97$ & $30,85 \%$ \\
$1.586 .053,64$ & $100 \%$ \\
$9.165,86$ & $0,58 \%$ \\
$86.065,53$ & $5,42 \%$ \\
$95.231,39$ & $6 \%$ \\
$6.216,96$ & $0,39 \%$
\end{tabular}

Fonte: UNINFRA (UEFS, 2017).

\section{Aspectos do meio físico}

Os aspectos do meio físico do campus foram analisados de acordo com a sua localização dentro do município de Feira de Santana - BA e no que diz a literatura, baseando-se, em sua maior parte, nos mapas e nas informações encontradas em Bastos (1996).

\section{Geomorfologia e Relevo}

Geomorfologicamente, o campus faz parte do Tabuleiro Interiorano Inumado, genericamente chamado de Tabuleiros de Feira de Santana, modelado de aplainamento. Já no que concerne ao relevo, predomina o plano.

\section{Geologia}

Levando em conta a localização do campus dentro do município e as características da textura das rochas (conglomerados de argila e areias, apresentando cores variadas, principalmente avermelhadas e apresentando concreções lateríticas ferruginosas em alguns locais), conclui-se que essas rochas pertencem ao pacote sedimentar. Havendo, também, rochas do complexo Jequié, gnaisses, granulitos e granitóides (metamórfica).

\section{Hidrologia}

O município pertence à bacia do rio Paraguaçu, estando assentado sobre um planalto divisor de águas de três sub-bacias: rio Jacuípe, rio Subaé e rio Pojuca. Nesse cenário, duas lagoas estão próximas do campus: Lagoa da Pindoba (Norte) e Lagoa da Tábua (Oeste). De acordo com suas localizações, essas lagoas são alimentadas pela subbacia do rio Jacuípe.

\section{Clima e Vegetação}

Como o campus da UEFS está inserido dentro do município de Feira de Santana, os dados do município foram utilizados como parâmetro para caracterizá-lo. Segundo estudos climatológicos feitos anteriormente, o município possui um clima quente e úmido com chuvas de verão. Sendo que a região é semi-árida.

Lê-se em Bastos (1996) que a região está inserida, quase globalmente, dentro da área da Floresta Estacional Decidual e Semidecidual. Conclui-se que o campus apresenta, predominantemente, uma vegetação remanescente do tipo Estepe (Caatinga), típica de regiões do semi-árido. 


\section{Material inconsolidado versus Solo}

O campus está inserido em uma área cujo material inconsolidado é constituído por um solo areno-silto-argiloso. No que diz respeito ao perfil pedológico, SANTANA \& SANTOS-PINTO (2008) diz que há ocorrência das seguintes classes de solos no campus: Argissolo Amarelo, Argissolo Vermelho-Amarelo, Neossolo Quartzarênico e Neossolo Litólico.

\section{Trabalho de campo}

A atividade de campo teve como objetivo o reconhecimento do meio físico e a análise da situação geoambiental da localidade: material inconsolidado, geologia, características do relevo e vegetação, vias de acesso, área construída, área em construção, área verde remanescente, presença de processos erosivos, pontos de descarte inadequado de resíduos sólidos e águas superficiais.

Tabela 2. Características encontradas no campo

\section{Material inconsolidado \\ Geologia \\ Relevo \\ Vegetação \\ Resíduos sólidos}

Processo erosivo

Situação da Lagoa Pindoba

Solo de textura arenosa - silto - argilosa. Predominando a textura
arenosa
Afloramentos de rochas pertencentes ao pacote sedimentar
(conglomerados de argila e areias) e rochas alteradas (metamórficas)
Predominantemente plano
Vegetação Estepe (Caatinga) remanescente
Presente em maior quantidade nos limites sudoeste e pequena porção
oeste do campus
Algumas estradas não pavimentadas apresentam esse problema
Pequeno espelho d'água e grande parte de cobertura vegetal

\section{Elaboração do Banco de dados no SPRING}

Para a elaboração de mapas temáticos e armazenamento de dados, utilizou-se um Sistema de Informações Geográficas (SIG) por meio do "software" SPRING 5.2.7, desenvolvido pelo Instituto Nacional de Pesquisas Espaciais (INPE). O resultado final do SPRING é um banco de dados geoespacial (geográfico, georreferenciado) da área em estudo. Esse banco de dados contém vários planos de informações que integrados obtém-se um mapa geral do campus (Figura 1), o qual apresenta a área das lagoas, os pontos colhidos em campo, as curvas de nível, o limite da universidade e uma representação da área construída.

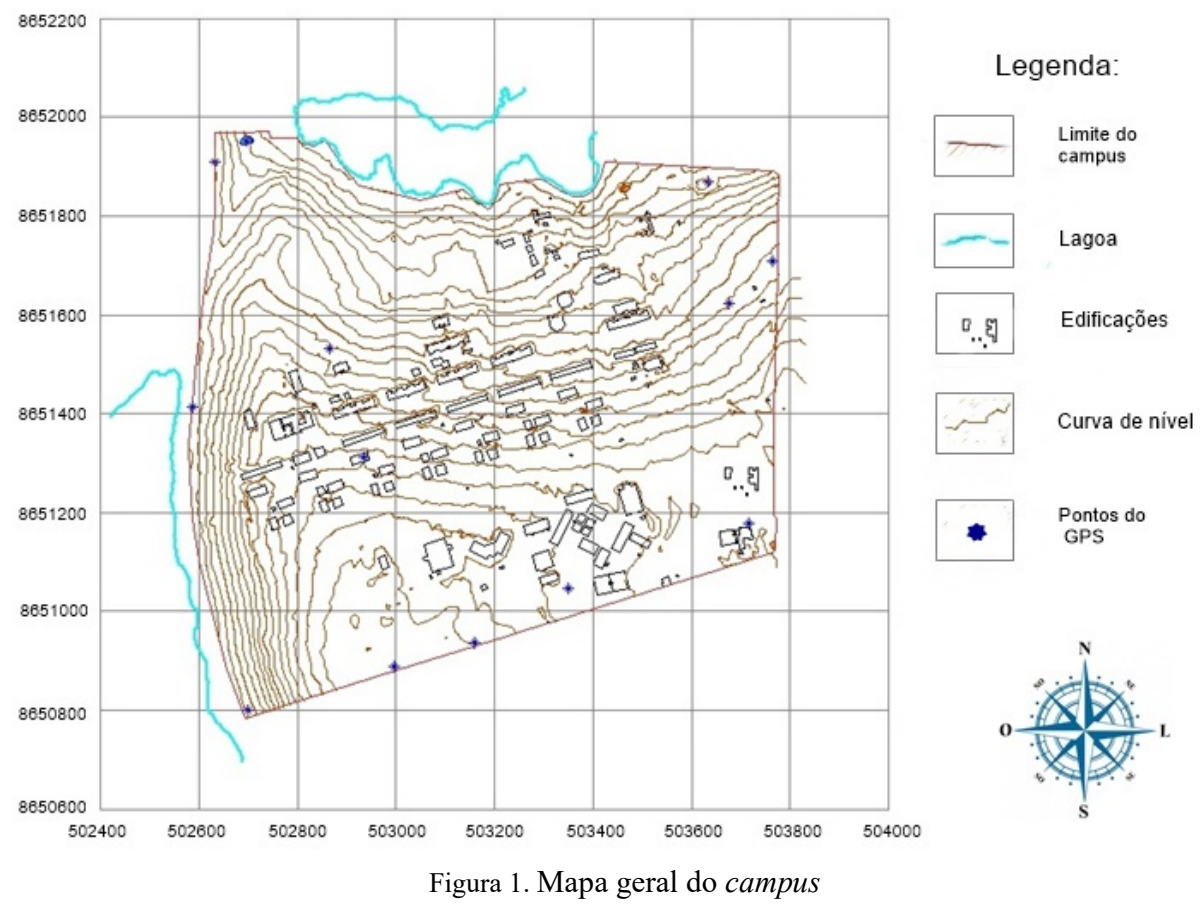




\section{CONSIDERAÇÕES FINAIS}

Os estudos geológicos e geotécnicos são instrumentos indispensáveis na análise do meio físico. Apresentar os resultados desses estudos sob a forma cartográfica é a maneira espacial de representar as informações, pois facilitam o seu entendimento e uso. E, para realizar esse trabalho, utilizou-se essa metodologia: a análise através do reconhecimento de campo e a representação das informações através do SPRING. Essa pesquisa possibilitou fazer um mapeamento geotécnico do campus e, a partir dessa caracterização, compreender o seu meio físico.

Com base em tudo que foi discutido e exposto ao longo da pesquisa (após o levantamento de dados, estudo e análise de informações e trabalho de campo), tem-se que o campus conta com um total de $86.065,53 \mathrm{~m}^{2}$ construído e $6.216,96 \mathrm{~m}^{2} \mathrm{em}$ construção, sendo que uma pequena parcela da cobertura vegetal ainda apresenta características da vegetação nativa (Estepe/ Caatinga). Além disso, o campus também conta com uma forte arborização. As classes de solos, em aspectos pedológicos, são: Argissolo Amarelo, Argissolo Vermelho-Amarelo, Neossolo Quartzarênico e Neossolo Litólico. O material inconsolidado é constituído por um solo areno-silto-argiloso. No que concerne à geologia local, a região se enquadra no pacote sedimentar-tercioquaternário, apresentando, também, rochas metamórficas. De acordo com a geomorfologia local, tem-se o Tabuleiro Interiorano Inumado, modelado de aplainamento. O relevo é predominantemente plano e essas características foram confirmadas quando se mediu elevações com o GPS e as compararam com as curvas de níveis do terreno, as mesmas variavam entre 235 a $255 \mathrm{~m}$.

Conclui-se que o campus da UEFS, no cenário ambiental, apresenta poucos focos de resíduos sólidos domésticos descartados de maneira indevida, entretanto, essa situação merece uma devida atenção para evitar a disseminação desses pontos de descartes inadequados. A respeito da hidrologia, duas lagoas estão nas imediações da universidade: Lagoa da Pindoba e Lagoa da Tábua, supostamente alimentadas pela subbacia do rio Jacuípe. A Lagoa da Pindoba se encontra pouco abastecida, apresentando um pequeno espelho d'água e uma grande parte coberta por vegetação. Também foram identificadas ocorrências de erosão em algumas estradas não pavimentadas, aparentemente, esse fenômeno foi causado, principalmente, pela ação das águas pluviais

\section{REFERÊNCIAS}

BASTOS, G. (1996). Estudo com Sistema de Informação Geográfica para o Mapeamento Geotécnico do Município de Feira de Santana - BA. Dissertação de Mestrado, Publicação GDM - 035A/96, Departamento de Engenharia Civil, Universidade de Brasília, Brasília, DF, 114.

SANTANA, C.M.F. ; SANTOS-PINTO, M. . Mapa dos solos do campus da Universidade Estadual de Feira de Santan (UEFS), Feira de Santana- Bahia. In: 44 Congresso Brasileiro de Geologia, 2008, Curitiba. Anais do 44 Congresso Brasileiro de Geologia, 2008. v. 1. p. 288-288.

"SPRING: Integrating remote sensingand GIS by object-oriented data modelling" Camara G, Souza RCM, FreitasUM, Garrido J Computers \& Graphics, 20: (3) 395-403, May-Jun 1996.

UEFS, Nosso Campus. Disponível em $<$ http://www.uefs.br/modules/conteudo/conteudo.php?conteudo=13>. Acesso em 01 de setembro de 2016.

UEFS. 2017. Unidade de Infra-estrutura e Serviços/Gerência de Projetos e Obras (UNINFRA). 